\title{
Globalización, sindicatos y migración laboral: Viejos dilemas, nuevas oportunidades
}

\author{
RONALDO MUNCK*
}

RESUMEN: El presente trabajo aborda las relaciones complejas, y en ocasiones conflictivas, entre los sindicatos y los trabajadores migrantes. Plantea los retos que la migración representa para los sindicatos en el contexto de la globalización y posteriormente analiza el tema de las mutaciones del sistema global desde la década de 1990 con base en la máxima de Gramsci: «Lo viejo ha muerto y lo nuevo no acaba de nacer». Asimismo, establece las bases para un análisis de los trabajadores en el contexto de la globalización y precarización bajo el argumento de que nos estamos alejando de las categorías de Norte y Sur en lo que a las mutaciones del capitalismo y su impacto en los trabajadores alrededor del mundo se refiere. Por último, examina la complejidad de la manera en que los trabajadores están respondiendo a las mutaciones del capitalismo, lo que constituye un desafío real a la reproducción estable del dominio capitalista y las oportunidades que surgen para un nuevo sindicalismo social global de escalas múltiples.

PALABRAS CLAVE: desarrollo, migración, sindicatos, trabajo, transformación.

\footnotetext{
* Profesor-investigador de Dublin City University, Irlanda.

Traducción del inglés de Mariana de la Vega y Helena de la Vega.
} 
ABSTRACT: This essay addresses the complex and sometimes conflicted relations between trade unions and migrant workers. We ponder the challenges which migration represents for trade unions in the context of globalization and the changing panorama of the global system since the 1990s on the basis of Gramsci's dictum that «the old has died but the new has not yet been born». This sets the scene for an analysis of workers in the context of the processes of globalization and precarization, arguing that we are now moving beyond the categories of North and South in terms of the mutations of capitalism and their impact on the workers of the world. Finally, we examine the complexities of the ways in which workers are responding to those mutations and are therefore posing a very real challenge to the stable reproduction of capitalist dominance and the opportunities arising for a new multi-scalar global social unionism.

KEYWORDS: development, migration, trade unions, labor, transformation. 


\section{Prefacio}

1 entrar en aguas desconocidas como resultado de la crisis global del capitalismo que comenzó en 2007, bien podríamos preguntarnos si representa una nueva oportunidad global para la clase trabajadora y las clases subalternas en general. En particular, pretendo abordar las relaciones complejas, y en ocasiones conflictivas, entre los sindicatos y los trabajadores migrantes. En primera instancia, planteo los retos que la migración representa para los sindicatos en el contexto de la globalización. De manera más profunda, examino los retos que para la teoría social progresista representa la crisis global actual. Abordo enseguida las mutaciones del sistema global desde la década de 1990 con base en la máxima de Gramsci: "Lo viejo ha muerto y lo nuevo no acaba de nacer». Este es el marco necesario para un análisis posterior de los trabajadores en el contexto de los procesos de globalización y precarización. La hipótesis que presento indica que nos estamos moviendo más allá de las categorías de Norte y Sur desde el punto de vista de las mutaciones del capitalismo y su impacto en los trabajadores alrededor del mundo (véase Munck, 2011). Por último, examino la complejidad, algunas veces subestimada, de la manera en que los trabajadores están respondiendo a las mutaciones del capitalismo, lo que constituye un desafío real a la reproducción estable del régimen capitalista. Delineo las limitaciones de una respuesta laboral a la explotación basada en los derechos y las oportunidades que surgen de un nuevo sindicalismo social global de escalas múltiples.

\section{Retos}

La cuestión de la migración laboral al interior de los países y entre ellos debe ser, sin duda, central para cualquier proyecto que busque la reconstrucción del orden económico mundial con base en el principio del desarrollo democrático. En la actualidad, comprendemos mejor la dimensión dual, social y espacial de la expansión del trabajo como fuerza laboral y movilidad laboral. 
Lo global se entiende ahora como un dominio mucho más complejo que el representado por la perspectiva eurocéntrica dominante de un núcleo dinámico y una periferia pasiva. Asimismo, estamos mucho más a tono con la dialéctica entre las divisiones de clase y otras, principalmente las que se basan en género y etnicidad. De igual forma, entendemos ahora la complejidad de la subsunción del trabajo al capital y las muy diversas formas que pueden tomar las relaciones sociales de producción (Banaji, 2011). Sin embargo, seguimos luchando para incluir los estudios de migración y los estudios sobre el trabajo dentro del mismo paradigma global, dado que la mayoría de los estudios de migración todavía operan conforme a una completa división entre los procesos de migración nacional y transnacional, probablemente como un extraño reflejo del nacionalismo metodológico.

En un intento por realizar un repaso de la historia mundial, la principal diferencia entre mediados del siglo XIX y el periodo actual es el cambio de la clase social al lugar social como el factor determinante de las oportunidades de vida. En términos muy generales, en 1850 aproximadamente la mitad de la desigualdad entre personas a nivel mundial podía explicarse por un desarrollo desigual entre los países y la otra mitad por las diferencias en el ingreso entre clases sociales. Hoy en día, de acuerdo con los cálculos realizados por Branko Milanovic, la división entre el lugar de ubicación y la clase social se aprecia de manera muy diferente: alrededor de 85 por ciento se debe a las diferencias entre la media del ingreso de los países y únicamente 15 por ciento a diferencias de clases sociales (Milanovic, 2011: 7). No tenemos que aceptar, como parece hacerlo él, que «un nuevo fantasma recorre el mundo», que esta vez no es el comunismo, sino la migración en masa desde los países pobres; pero lo que claramente significa es que el imperialismo o el neocolonialismo tiene un impacto en el trabajo tanto como, o no más que, la clase social y que la migración laboral tiene decididamente una lógica socioeconómica.

Hoy en día los sindicatos enfrentan muchos retos como resultado de un cuarto de siglo de globalización neoliberal y la consecuente descomposición del trabajo. La migración, esto es, la movilidad laboral libre, tradicionalmente se ha visto como un problema para los sindicatos. Se ha considerado a los trabajadores migrantes como una amenaza a las normas laborales bien esta-

$6 \frac{\text { SEGUNDO SEMESTRE } 2014}{\text { MIGRACIÓN Y DESARROLLO NÚM. } 23}$ 
blecidas y, de hecho, como un sector «difícil de organizar». Así como los trabajadores están divididos por género, edad y etnicidad, también están divididos de acuerdo con su nacionalidad y estatus de ciudadanía. Lo que propongo en el presente artículo, en función de transformar la crisis mundial del capital en una oportunidad mundial del trabajo, es un cambio decisivo hacia la migración como una bisagra para el futuro de la globalización y como una oportunidad para la revitalización de los sindicatos con miras a una transformación social. Dentro de una coyuntura histórica en la que el proteccionismo nacional, la xenofobia y el racismo están destinados a tomar un lugar preponderante, este enfoque podría, como mínimo, desempeñar un papel positivo en relación con la defensa de la democracia y, posiblemente, en impulsar una transformación social.

A lo largo de la historia los sindicatos, como organizadores del «factor de producción» denominado trabajo, han mostrado en la práctica, sino es que programáticamente, una actitud proteccionista hacia la movilidad laboral libre. ${ }^{1}$ Existen numerosos ejemplos en la historia de los sindicatos que se oponen a la entrada de trabajadores extranjeros al mercado laboral nacional o que buscan la exclusión social de los que ya están en él (véase Penninx y Roosblad, 2001). Recientemente ha habido un reconocimiento, desde el interior de los sindicatos mismos, de que «la solidaridad con los trabajadores migrantes está ayudando a los sindicatos a volver a los principios básicos del movimiento laboral» (David, 2002: 2). Uno de los argumentos afirma que

${ }^{1}$ Los sindicatos tradicionalmente se han opuesto a la migración, la cual es vista como un elemento que debilita las fortalezas para las negociaciones locales. Sin duda, los patrones históricamente han importado fuerza laboral «rompehuelgas» con el fin de socavar las huelgas. En los países receptores - ya sea en América Latina a principios del siglo xx o en Europa en la actualidad- los sindicatos (y los partidos socialistas) se han mostrado reticentes y dudosos de las iniciativas gubernamentales que buscan alentar la inmigración. Los trabajadores migrantes pueden entonces formar parte integral del movimiento laboral nacional, "nacionalizarse» o mantener y permanecer a cierta distancia. En Europa, hasta hace poco tiempo, hubo ejemplos de trabajadores migrantes a quienes no se les permitía establecer un papel significativo en un sindicato (véase Penninx y Roosblad, 2000). Los sindicatos, dado su papel en los mercados laborales nacionales, también buscarán tener influencia en el Estado dependiendo de qué categorías de trabajadores puedan o no entrar al país. Por supuesto que también pueden cambiar su posición como lo hicieron en Estados Unidos recientemente, y volverse más «promigrantes». 
para «democratizar la globalización» debe prevalecer el mismo nivel de movilidad laboral que se aplica a nivel nacional. Los sindicatos latinoamericanos se han dado a la tarea de "promover, incrementar, fortalecer y garantizar la libertad de movimiento para todos los trabajadores [...] [y] de permanecer en su propia tierra, emigrar, inmigrar y regresar» (Godio, 2005: 56). Un movimiento laboral dinámico debe reconocer que los trabajadores migrantes son una parte integral de la clase trabajadora y que con frecuencia han desempeñado un papel fundamental en la creación de movimientos laborales. ${ }^{2}$

En años recientes, los sindicatos en casi todo el mundo han comenzado a recuperarse del impacto del neoliberalismo y su estrategia de mercado no regulado. Esto ha alcanzado su nivel máximo con la formación de una confederación sindical unificada como resultado del fin de la Guerra Fría. La antigua Secretaría Internacional de Sindicatos (ITS, por sus siglas en inglés) también cobró nueva fuerza como el nuevo Consejo Mundial que se organiza internacionalmente en un sector en particular. A nivel nacional, ha habido un resurgimiento de los sindicatos en algunas regiones como América Latina, en tanto que en Estados Unidos hubo una marcada radicalización política en el punto máximo. Un número creciente de literatura académica sobre la

${ }^{2}$ Los migrantes no son, por supuesto, una parte de la clase trabajadora nacional que no presenta complicaciones. Por definición, han dejado el mundo productivo y las relaciones sociales de la nación de la que eran parte. La academia ha desarrollado recuentos interesantes de las vidas "transnacionales» complejas de los migrantes. Sin embargo, no sólo son precursores de una nueva posición sociológica. Guillermo Almeyra ha escrito sobre la forma en que la emigración ha despoblado vastas zonas rurales de México, ha cambiado las características demográficas, ha dejado atrás vastas extensiones de tierras sin producir y, de manera todavía más controversial, ha creado un movimiento social masivo "conservador» $\mathrm{y}$ «antinacional» (Almeyra, 2008: 89). Jugando un papel de válvula de escape para el descontento rural, la emigración sin duda ha evitado el estallido de más casos como el de Chiapas, en donde la revuelta zapatista perdura en aislamiento. En contra del elogio profesado por los antropólogos culturales hacia el sincretismo cultural, Almeyra condena la forma en que la emigración perpetúa la visión de que el modelo estadounidense es al que hay que aspirar y que las soluciones individuales, en oposición a las colectivas, son la respuesta. Almeyra es un marxista revolucionario de tiempo atrás que debe mencionarse al evaluar esta crítica implícita de la ortodoxia de los estudios de migración. 
revitalización ${ }^{3}$ sindical ha podido comprobar a nivel transnacional los avances en áreas clave de actividades tales como la organización de nuevos sectores de trabajadores, una mayor actividad política, la reforma de la estructura sindical, la construcción de coaliciones y, no menos importante, un incremento en la actividad solidaria internacional (Frege y Kelly, 2003). Podríamos argumentar que estamos en el inicio de una fase en la que el sindicalismo se reconfigurará de nueva cuenta y se revitalizará para satisfacer las nuevas condiciones a las que se enfrenta.

El trabajo siempre ha mostrado una adaptación lenta a las mutaciones y crisis del capital. No sorprende que haya habido un retraso de 25 años entre la ofensiva capitalista neoliberal y la recomposición laboral, y que se adecue al patrón de las olas de desintegración y recomposición laboral de los siglos XIX y xx (Arrighi, 1990: 348). Esta naturaleza cíclica de las relaciones entre el trabajo y el capital parece haber sido ignorada por los analistas alrededor de 2000, quienes probablemente reflejaron el ambiente prevaleciente en el momento en que el capitalismo estadounidense ya había roto la naturaleza cíclica del capitalismo. Así, Castells argumentaba que: «El movimiento de los trabajadores parece haber sido superado históricamente» (Castells, 2010: 425), ya que en tanto el capital es global, el trabajo es local: «el trabajo es desagregado en su desempeño, fragmentado en su organización, diversificado en su existencia, dividido en su acción colectiva» (Castells, 1996: 475).

${ }^{3}$ Los debates sobre la «revitalización» de los sindicatos se han incrementado en los últimos años en respuesta a las distintas formas en que el movimiento sindical ha comenzado a reestructurarse después del neoliberalismo. Frege y Kelly (2003) resumen los principales hallazgos en relación con los países industrializados alrededor de cinco arenas principales: reestructuración organizacional (a través de fusiones y reorganización interna), construcción de coaliciones (con otros movimientos sociales), asociación con patrones (nuevos marcos de negociación), acción política (en relación con el Estado) y enlaces internacionales (por ejemplo, a nivel europeo). Por supuesto que los resultados son dispares en todos los países y en las cuestiones donde se han acumulado compromisos nuevos. Quizá podamos suponer que muchas de estas cuestiones también son aplicables a los países semi-industrializados como Brasil, Sudáfrica y Filipinas. Podríamos también preguntarnos si algunos de los elementos implican un retroceso hacia negociaciones colectivas tradicionales o modelos corporativistas, en tanto otros con un movimiento social o una orientación internacional apuntan más hacia un papel progresivo del trabajo. 
En tanto algunos de estos puntos eran coyunturalmente correctos, su análisis general ignoraba que el trabajo es un movimiento social. Una visión a largo plazo del último siglo mostraría que los sindicatos no sólo han perdurado, sino que también han estado «creando sociedades más democráticas, más respetuosas de los pobres, trasladando a los derechos humanos por encima de los reclamos de la propiedad capitalista» (Friedman, 2008: 10). No es un logro menor dada la brutalidad de la contrarrevolución neoliberal.

Si la actual crisis plantea un reto al movimiento de los trabajadores, también requiere una respuesta más sólida de parte del pensamiento social crítico que la que hemos visto hasta ahora. En cierto nivel, la actual crisis del capitalismo justifica la lectura marxista tradicional del capitalismo y sus contradicciones; esto ha sido reconocido a lo largo del espectro político - aunque de mala gana- desde el estallido de la crisis en 2007. Desde la última gran crisis del capitalismo en la década de 1930, el sistema mundial se ha embarcado en dos regímenes políticos principales. El keynesianismo condujo al régimen del «liberalismo enraizado» de Bretton Woods (Ruggie, 1984), que duró hasta aproximadamente 1975, permitiendo la asignación de recursos del mercado, pero restringido por el proceso político, y permitiendo las necesidades sociales. A esto siguió la «hipótesis del mercado eficiente» neoliberal (Farmer y Lo, 1999) que establecía la justificación para la globalización y la expansión de un nuevo orden económico mundial. Hoy nos enfrentamos al enigma de un "cambio de régimen financiero» (Wade, 2008) que los poderes al mando no encontrarán más fácil de resolver que el «cambio de régimen» que Irak llevó a cabo cuando la arrogancia estadounidense alcanzaba su punto máximo en todo el mundo.

El marxismo clásico nos permite comprender la recomposición de la clase trabajadora a escala global en aproximadamente los últimos 30 años. La naturaleza dinámica - aunque destructiva - de este sistema no es menos evidente con el surgimiento de los países del BRIC (Brasil, Rusia, India, China) como centros dinámicos de expansión y acumulación del capital en un modo "clásico». Se están formando nuevas clases trabajadoras en estos regímenes y el futuro de la lucha de clases dependerá, en gran medida, de su resultado.

$10 \frac{\text { SEGUNDO SEMESTRE } 2014}{\text { MIGRACIÓN Y DESARROLLO NÚM. } 23}$ 
Como lo afirma Mike Davis en forma lacónica: «Doscientos millones de obreros fabriles, mineros y obreros de la construcción en China son la clase más peligrosa del planeta. (Preguntémosle si no al Consejo de Estado en Pekín). Su despertar de la burbuja podría determinar si es o no posible una Tierra socialista» (Davis, 2011: 15). Sin embargo, lo que necesitamos añadir a esta perspectiva marxista es la comprensión de la forma en que la "acumulación originaria» continúa operando a través de la «acumulación por desposesión", ${ }^{4}$ una perspectiva "tercermundista» articulada en su tiempo por Rosa Luxemburgo en contra de Lenin y los demás marxistas ortodoxos de su tiempo.

Karl Polanyi — proveniente de una tradición socialista europea, pero también influenciado por un pensamiento cristiano- desarrolló un nuevo y arriesgado paradigma de desarrollo capitalista después de la Segunda Guerra Mundial. En tanto una buena parte de su análisis sobre el desarrollo capitalista es reconocidamente marxista, se distancia de su tradición analítica en diversos puntos clave. Su tesis amplia y detallada de un «doble movimiento» — desregulación del mercado seguida de una sociedad que se protege a sí misma- entendió que la globalización neoliberal tenía sus límites. Las protestas en contra de la degradación ambiental, los movimientos en contra de los tratados de "libre comercio» o las luchas en contra de la clausura de fábricas podrían encontrar un hilo unificador ahí. Polanyi argumentaba en forma explícita en contra de Marx que el trabajo no era una mercancía:

${ }^{4}$ La «acumulación por desposesión» es un término acuñado por David Harvey (2003) para describir la operación actual de la «acumulación originaria» en la era de la globalización. Esta apropiación, de separación de la producción, no puede restringirse al periodo del surgimiento del capitalismo. Por el contrario, Harvey sostiene que la «acumulación por desposesión»es un proceso continuo dentro de la acumulación de capital a escala global. Logra tener acceso a materias primas más baratas así como a mercados en expansión y esto ayuda a mantener las ganancias y la tendencia del capitalismo hacia la «sobreacumulación» acorralada. Asimismo, Harvey actualiza la concepción original de Marx al mostrar la forma en que puede ser aplicable a los derechos de propiedad intelectual, la privatización y la depredación ambiental. En el primer caso, se hace evidente en la forma en que las farmacéuticas se adueñan del conocimiento médico tradicional, por ejemplo, y también en la privatización de la explotación minera, otro ejemplo que constituye el medio por el cual los «bienes del dominio público» están pasando a manos privadas para obtener una ganancia. 
«El trabajo es sólo otra forma de denominar la actividad humana que forma parte de la vida misma, no puede ser tiranizada, ser usada en forma indiscriminada, o incluso dejarse de usar sin afectar también al individuo que además es el portador de este bien específico» (Polanyi, 2001: 75-76).

En relación con la desmercantilización (decommodification) Polanyi proporciona, probablemente, su más poderosa perspectiva estratégica sobre los movimientos actuales, más allá del neoliberalismo. El mercado autorregulado no integrado socialmente, inevitablemente se verá desafiado por las tendencias autoprotectoras de la sociedad. Así, por ejemplo, de acuerdo con Polanyi, la función de los sindicatos no era obtener un precio más alto por el trabajo como producto básico, sino «el de interferir con las leyes de oferta y demanda en relación con el trabajo humano y de retirarlo de la órbita del mercado» (Polanyi, 2001: 186). Todos los movimientos provenientes del interior del terreno social se enfocaron en restringir la operación no regulada del mercado - la desmercantilización-y, por lo tanto, en desafiar los fundamentos de la economía de mercado. La estrategia de desmercantilización y de reintegración de la economía dentro de la sociedad puede fungir como una "lógica de la equivalencia» ${ }^{5}$ que actúa para articular un rango de luchas protectoras o defensivas muy diversas por naciones, clases y grupos étnicos subalternos. Este es, desde mi punto de vista, un suplemento necesario al análisis marxista clásico del capitalismo y sus contradicciones.

${ }^{5} \mathrm{La}$ «lógica de la equivalencia» forma parte de la crítica antiesencialista del marxismo tradicional que hace Ernesto Laclau (2005), que busca reinscribir la política en la lucha por la emancipación. Rechaza el esencialismo de clases y un papel privilegiado preestablecido para el proletariado. Por el contrario, desarrolla la noción de hegemonía de Gramsci y la necesidad de construir una democracia radical a través de una "guerra de posiciones». En la construcción discursiva del antagonismo, la lógica de la equivalencia es una de condensación que separa el campo simbólico en un «nosotros y ellos». Existe una pluralidad de relaciones de subordinación que necesita encontrar una lógica de equivalencia si se pretende que se haga responsable de la emancipación. Podemos encontrar este proceso puesto en práctica claramente en la creación de identidades de pueblo a través de revoluciones populistas, anticolonialistas e incluso revoluciones socialistas existentes. Queda por ver si la alterglobalización puede generar una hegemonía alternativa a través de una lógica de la equivalencia, lo que en la actualidad parece poco probable. 


\section{Mutaciones}

Parece evidente que estamos ahora viviendo un periodo histórico similar al que Antonio Gramsci caracterizara como uno en que «lo viejo ha muerto y lo nuevo no acaba de nacer» (Gramsci, 1970: 276). Si bien es cierto que la globalización neoliberal continúa dominando, ya no tiene hegemonía. Las estrategias de la clase dominante están desarticuladas en todo el mundo y en algunas regiones esto ha alcanzado un punto de crisis. ̇̇Estamos ante una de esas coyunturas en las que las principales mutaciones del sistema están a punto de ocurrir? ¿Cuáles son las posibilidades para la elaboración de una hegemonía alternativa que surja de las naciones, las clases y los grupos religiosos y étnicos subalternos? Cualesquiera sean nuestras respuestas a estas difíciles preguntas, considero que podemos estar de acuerdo en la necesidad de formularlas en forma afirmativa. Demasiadas intervenciones en torno a los trabajadores y migrantes (sin mencionar el precariado) se formulan de manera defensiva como una reacción a la violación de los supuestos derechos humanos. Es el momento de construir un pensamiento hegemónico alternativo y darle forma a la expresión, hasta este punto, inane de que "otro mundo es posible» (Santos, 2006).

El modelo económico dominante generó una transformación social en masa a través de la globalización, la desregulación financiera, la privatización y la mercantilización (commodification) del curso de la vida. La desregulación de los mercados financieros, como lo reconoce ahora la zona del euro, creó una serie de burbujas de activos que alcanzó su punto crítico en Estados Unidos en 2007. Un sistema bancario en la sombra había aventajado al sector bancario regulado. Por lo tanto, como lo expresa Robin Blackburn: «La búsqueda imprudente por parte de los bancos de ventajas a corto plazo llevó a la destrucción más grande de valor en la historia del mundo durante la gran crisis financiera de 2008. Las medidas de rescate puestas en práctica por el gobierno ofrecían una liquidez ilimitada al sector financiero, en tanto que dejaban el sistema en gran parte intacto» (Blackburn, 2011b: 35). Esto es, las ideologías neoliberales y sus seguidores han perdido la hegemonía, pero siguen 
siendo dominantes. En tanto el keynesianismo es la inspiración intelectual para todo tipo de críticas a la crisis, no se ha construido aún un camino alternativo coherente $y$, de hecho, la mayoría de las contramedidas simplemente acentuarán la crisis a través de las llamadas medidas de austeridad en contra de los trabajadores.

$\mathrm{Al}$ inicio de la crisis, los comentaristas convencionales depositaron sus esperanzas en los países BRIC, a los que se percibían de alguna manera ajenos a la crisis financiera. China e India podrían bajar su ritmo de crecimiento pero actuarían como motores de la recuperación global. Había esperanzas puestas en el sector informal, que actuaría como una red de seguridad para los que habían perdido sus empleos. El antiguo economista en jefe del Fondo Monetario Internacional (FMI) nos dijo que: "La situación en países desesperadamente pobres no es tan mala como se pensaría» (citado en Bremen, 2009: 30). En la realidad, pronto se vio que la crisis alcanzaba niveles mundiales - una consecuencia inevitable de la globalización-y que era, por lo tanto, claramente sistémica. La tan aclamada Nueva Era tecnológica no se había materializado. La oferta pública inicial de Facebook y las energías renovables difícilmente generarían un nuevo modelo de crecimiento acelerado. En cuanto a los países BRIC, el crecimiento derivado de las exportaciones se ralentizó en medio de la recesión global y ahora se prevé un «aterrizaje forzoso» para China. Se perfila una «recesión global absolutamente triangulada» (Davis, 2011: 14), donde Estados Unidos, Europa y los países BRIC están involucrados en un escenario de una «tormenta perfecta» que ni siquiera Karl Marx hubiera podido imaginar.

El impacto de la crisis en los trabajadores y en los trabajadores migrantes y, en particular, en los trabajadores migrantes fue masiva y se desenvolvió rápidamente. La globalización ha creado un mundo económica, social y espacialmente mucho más integrado. Las diásporas laborales han formado redes sociales densas íntimamente integradas en la expansión espacial del capitalismo. En consideración a estas redes, David Harvey afirma que «vemos ahora los efectos del colapso financiero esparcirse en casi cada rincón del África rural y la India campesina» (Harvey, 2010: 147). En los países de la Organización para la Cooperación y el Desarrollo Económicos (OCDE), el

$14 \frac{\text { SEGUNDO SEMESTRE } 2014}{\text { MIGRACIÓN Y DESARROLLO NÚM. } 23}$ 
papel del desempleo está escalando rápidamente con fallas sistémicas que están destinadas a multiplicarse. Cuando los jóvenes indignados se reúnen en las plazas de España, sus oportunidades de vida no son tan diferentes, cualitativamente, de las de sus contrapartes en el norte de África. Éste no era el caso en 1968: la distancia social entre un estudiante de Berkeley y un campesino vietnamita era infranqueable. En cuanto a la migración global, el escenario es poco claro. Es un hecho que no hemos visto el fin de la migración. Es más probable que veamos una transformación de los regímenes de la migración en donde emergerán nuevos países como unidades de origen y de acogida, así como una «agitación» real de los flujos existentes.

En tanto algunos analistas representan a las masas subalternas como una «multitud», ${ }^{6}$ no ofrecen una estrategia hegemónica alternativa. Hacia el final de Imperio, Hardt y Negri (2001) apuntan a la necesidad de un programa político para la multitud global sin ir más allá de unos cuantos lugares comunes. Sin embargo, plantean algunas cuantas cuestiones - como el derecho a una "ciudadanía global»- expresadas en el lenguaje tradicional de los derechos y las demandas. Cómo puede lograrse esto, y a través de qué mecanismos políticos, no se explica. Las luchas no se relacionan en forma horizontal, todas desafían al imperio en forma vertical y directa. Esta visión absolutamente apolítica puede encontrar eco en corrientes «autonomistas» pero no es capaz de articular las diversas y dispares luchas en contra del orden dominante en curso. Como lo expresa Laclau: «cualquier "multitud" se construye a través de la acción política, lo cual presupone la existencia de

${ }^{6}$ «Multitud» es un término maquiavélico recientemente revivido por Hardt y Negri como un nuevo agente de resistencia en contra del capitalismo global. La multitud se concibe como un sujeto social sin mediación, inmanente, que desafía al imperio. El nomadismo universal ha creado nuevas figuras de lucha y nuevas subjetividades que expresan y nutren a un nuevo proyecto constituyente. El poder desterritorializador de la multitud es la fuerza productiva que sostiene al imperio en tanto que expresa la fuerza que hace necesaria su destrucción. Hardt y Negri no ofrecen un programa o estrategia política: «Sólo la multitud a través de su experimentación práctica ofrecerá los modelos y determinarán cuándo y cómo lo posible ha de hacerse real» (Hardt y Negri, 2001: 411). No hay una lógica de equivalencia en tanto todas las luchas son inconmensurables. El sujeto revolucionario es inmanente y por lo tanto no necesitamos preocuparnos con la acción política o la construcción de una hegemonía alternativa. 
antagonismo y hegemonía» (Laclau, 2011: 133). La suma espontánea de luchas dispares no puede llevarse a cabo sin las articulaciones políticas necesarias y el establecimiento de una lógica de equivalencia entre ellas.

Dentro del movimiento sindical, y todavía más al interior de las organizaciones no gubernamentales (ONG) internacionales (mal llamadas por algunos la «sociedad civil global»), ha habido una tendencia a responder a la crisis desde una perspectiva de derechos humanos. Un primer ejemplo es el Programa de Trabajo Decente (DWC, por sus siglas en inglés) promovido por la Organización Internacional del Trabajo (OIT), el movimiento sindical internacional y la Comisión Europea. Se trata de un concepto y un programa basados en el entendimiento de que el trabajo es una fuente de dignidad personal, estabilidad familiar y paz en la comunidad, de democracia en beneficio de todos y de crecimiento económico que aumenta las oportunidades de trabajo productivo y el desarrollo de las empresas. Su principal objetivo es «lograr el reconocimiento y el respeto de los derechos de los trabajadores» (OIT, s/f). Aunque retomaré sus limitaciones como estrategia laboral contemporánea en algunas líneas, quiero enfatizar de manera más general las limitaciones de una estrategia basada en derechos. Este no es el lugar para evaluar la cuestión, más amplia, de si el movimiento de derechos humanos internacional es más parte del problema que de la solución; sin embargo, debemos hacer notar que el régimen de derechos humanos refleja la ética y la política de un periodo en particular de Europa occidental. Probablemente sea cierto también que promete más de lo que puede cumplir. Sin duda ha servido por momentos a legitimar la represión y el mal gobierno. El único punto que deseo enfatizar aquí, siguiendo las ideas de Kennedy, es que: «Los derechos humanos han dominado de tal manera el espacio imaginativo de la emancipación, que ahora sólo puede pensarse en las alternativas [...] como negaciones a lo que reafirman los derechos humanos: pasión a la razón, local a lo global, etc.» (Kennedy, 2001: 108). En resumen, una visión de derechos humanos puede obstaculizar el desarrollo de una política de transformación elaborada para la era actual. Necesitamos siempre tener en cuenta, 
como nos lo recuerda Kennedy, que «hablarle de derechos a la política no es lo mismo que hablarle al poder con la verdad» (Kennedy, 2001: 121).

Los trabajadores migrantes no sólo - o incluso principalmente- están organizados a través de sindicatos, sino también a través de organizaciones específicamente orientadas a los migrantes, ya sean organizaciones que promueven la etnicidad, la fe u otra cuestión. Existe un rango amplio de organizaciones no gubernamentales o comunitarias que se enfocan en la organización de los migrantes qua migrantes. Muchas de éstas se enfocan en los derechos humanos de los migrantes, en particular en los derechos ciudadanos de los inmigrantes. Esto resulta irónico porque, como lo afirma Piper: "Los derechos de los migrantes son uno de los grupos, sino es que el grupo, de derechos humanos menos claros y regulados que focaliza a los grupos marginalizados» (Piper, 2009). Ciertamente, algunas organizaciones dirigidas por migrantes se enfocan en la organización política y están abiertas a hacer alianzas con movimientos laborales organizados, por ejemplo. En general, sin embargo, la mayor parte del activismo de las ONG a favor de los migrantes muchas veces tiene una orientación hacia la crisis o la reparación, tal como lo expresa Piper: "Dichas intervenciones en casos de crisis o "servicios ambulatorios" no se orientan generalmente hacia el activismo» (Piper, 2009).

Existe un incremento particularmente notorio en la organización de trabajadoras migrantes. La dimensión de género de estas trabajadoras ha destacado especialmente a partir de las campañas emergentes regionales y globales como las que giran alrededor de las trabajadoras domésticas migrantes. Las campañas orientadas hacia las mujeres se han comprometido con los derechos de género de estas trabajadoras, aunque no siempre aliándose con los defensores de los derechos laborales. Hasta hace poco, la mayor parte del énfasis estaba puesto en las migrantes como víctimas, con el discurso y el problema de la trata de personas en primer plano. Sin embargo, cada vez más las migrantes están desarrollando una voz autónoma, tanto en los países de origen como de acogida, con la esperanza de que esto pueda ayudarlas a superar la fragmentación y el aislamiento mutuo actual. Existe una laguna en la literatura sobre las trabajadoras migrantes en su calidad de migrantes (estudios de 
migración) o en su calidad de trabajadoras (estudios laborales) y, como lo expresa Lyons, es raro ver «que se haga énfasis en su identidad compleja como trabajadoras migrantes» (Lyons, 2006: 3).

Podríamos llegar a una conclusión general respecto a la necesidad de construir alianzas más concertadas entre los sindicatos, las ong y las organizaciones comunitarias en torno a las demandas y las necesidades de los trabajadores migrantes como sujetos condicionados por el género. En la actualidad, diferentes historiales de organización, la falta de solidaridad y una perspectiva unificadora poco clara ha obstaculizado estos esfuerzos. También se necesita una perspectiva académica a niveles múltiples para articular de manera clara los derechos de los trabajadores y de las mujeres a niveles local, nacional y transnacional. A partir de estos debates podría surgir, como Lyon sugiere, "la capacidad de encontrar un "terreno común" desde el cual abordar las necesidades de las trabajadoras migrantes» (Lyons, 2006: 15). Podemos emprender esta búsqueda en particular a través de la lente feminista de interseccionalidad (Lutz et al., 2011) que se enfoca en el eje múltiple, y con frecuencia simultáneo, de identidad que contribuye a la desigualdad social entre las mujeres, tales como el género, la raza y la clase, entre otros. Esta conceptualización multidimensional es igualmente aplicable a los trabajadores migrantes y su posicionalidad e identidad interseccional.

Básicamente, la lucha de los trabajadores - a través de los sindicatos y otras entidades - no es una esfera separada de la lucha más amplia por la transformación social. Tampoco es la migración laboral una esfera separada, tal como Stephen Castles (2010) lo afirmó recientemente, sino, por el contrario, una parte del proceso general de transformación social. De esta forma, por ejemplo, las luchas por los derechos de los trabajadores en Egipto no pueden separarse de las transformaciones sociales, políticas y culturales cruciales en vías de ejecución en ese país. Una perspectiva de «derechos humanos» de la Organización de las Naciones Unidas (ONU) o de una ONG tiene también, sin duda, bastantes limitaciones fuera del dominio retórico. El mundo de los trabajadores que vemos ahora siempre ha conocido el valor de la política, de la acción directa, de las luchas de masas y de la comprensión de que la transformación social se basa en la lucha.

$18 \frac{\text { SEGUNDO SEMESTRE } 2014}{\text { MIGRACIÓN Y DESARROLLO NÚM. } 23}$ 


\section{TRABAJADORES}

La clase trabajadora - el proletariado de Marx — vio la luz con el surgimiento del capitalismo como modo de producción caracterizado por el trabajo «libre» remunerado. La coerción extraeconómica dio lugar a la compulsión vacua de las fuerzas del mercado. La dimensión internacional, y el papel de los trabajadores migrantes en particular, fue crucial en esta etapa temprana de creación de la clase trabajadora (Linden, 2003). La migración libre a través de las fronteras nacionales fue considerada natural y la xenofobia no era común; el internacionalismo, en el sentido económico, no fue, por lo tanto, forzado. Pero esta fase temprana internacionalista duró poco en la medida en que la formación de Estados comenzó a dirigir la integración nacional de las clases trabajadoras europeas en particular, lo que culminó en la primera guerra entre imperios de 1914 a 1918. Los sindicatos se «nacionalizaron», por así decirlo, convirtiéndose en un elemento integral de la cohesión social y política dentro de los límites de un Estado-nación en particular. La formación de sindicatos en el llamado mundo en vías de desarrollo, seguido de una segunda guerra entre imperios de 1938 a 1945, también tomó un carácter fuertemente nacional con los trabajadores y sus organizaciones, que jugaron un papel clave en numerosas luchas de liberación nacional.

Tanto Karl Marx como Karl Polanyi comprendieron que el capitalismo no alcanzaría su máximo potencial hasta que estuviera globalizado. Para Marx y Engels, en el Manifiesto Comunista: «La burguesía, al explotar el mercado mundial, da un sello cosmopolita a la producción y al consumo de todos los países. En lugar del aislamiento y la autosuficiencia locales y nacionales antiguas, tenemos relación en todas direcciones, interdependencia universal de las naciones». Polanyi, para un periodo histórico distinto, escribió que: «Las verdaderas implicaciones del liberalismo económico pueden percibirse ahora con un vistazo. Nada menos que un mercado autorregulador a escala mundial podría asegurar el funcionamiento de este mecanismo estupendo» (Polanyi, 2001: 145). La globalización — tal como se desplegó desde la década de 1980 - transformó por completo el mundo laboral. En primer lugar, hubo un incremento masivo de la proletarización mientras 
millones de personas eran cobijadas bajo la influencia del capital. Los regímenes de desarrollo nacional pronto fueron sustituidos junto con el sistema del Estado socialista. Esto condujo a un cambio de la supeditación formal del trabajo a la real. Sin embargo, en segundo lugar, es necesario hacer notar que esta proletarización global tuvo lugar bajo la protección del imperialismo y estuvo por lo tanto marcada por un patrón racista.

El trabajo en la era global se caracterizó, principalmente, por una movilidad cada vez mayor, dentro y entre los Estados-nación. En 1970 había 82 millones de personas viviendo fuera de su país de origen; para 2000 esta cifra se había incrementado a 175 millones. No obstante, es pertinente recordar que los migrantes internos en China e India llegan probablemente al doble de esa cifra y que siempre debemos tomar a la migración como un todo desde una perspectiva de desarrollo. Los trabajadores migrantes representan, en algunos aspectos, un retorno a los patrones de trabajos forzosos de la época colonial en la medida en que la exportación de trabajo barato (o su transferencia dentro de un país) se vuelve un camino viable y legítimo de desarrollo. Es posible que Hardt y Negri suenen apocalípticos, pero existe un halo de verdad en su declaración de que: "Un fantasma recorre el mundo y es el fantasma de la migración» (Hardt y Negri, 2001: 213). El problema es traducir esta nueva realidad compleja a una política de transformación que vaya más allá del elogio de la partida como una respuesta a la opresión. Los migrantes se encuentran en una posición liminar en y entre las fronteras o la división rural/urbana, parcialmente móvil, parcialmente establecida; representan un desafío al movimiento laboral (establecido) organizado, como hemos argumentado, pero también para los administradores de la globalización y será un caso de prueba al evaluar si se puede alcanzar el desarrollo global sostenible.

La otra característica clave de la condición laboral en la era de la globalización es la de la flexibilidad, que se convirtió en el leitmotiv de la reestructuración neoliberal del trabajo. La flexibilización del trabajo fue un imperativo clave para globalizar el capital: involucraba la flexibilidad funcional, la flexibilidad salarial y la flexibilidad numérica. Este empuje tuvo una naturaleza global, aunque tomó diferentes formas nacionales de acuerdo con el grado y 
el tipo de integración del mercado laboral y con la fuerza del movimiento laboral. Este último respondió con un llamado a que se incluyera una «cláusula social» en los tratados comerciales multilaterales para evitar el «dumping social» entre las fronteras. Al final del día, hubo poco que mostrar de esta campaña más allá de unos cuantos convenios en papel de compañías europeas. Las viejas estrategias laborales estaban destinadas a fracasar, dado que el terreno establecido por el capital había cambiado de manera tan drástica. La flexibilización no era sino una parte de una estrategia concertada por el capital para debilitar el trabajo a través de la completa desregulación y una llamada «informalización» de las relaciones de producción.

Probablemente las mutaciones más prominentes de la economía política global del trabajo pueden encapsularse en el término brasilización, empleado por primera vez por el sociólogo alemán Ulrich Beck (2000). Para Beck: «La consecuencia no intencionada de la utopía neoliberal del mercado libre es la brasilización de Occidente [...] [,] la expansión del empleo temporal e inseguro, la discontinuidad y la informalidad laxa hacia las sociedades occidentales que hasta el momento habían sido los bastiones del pleno empleo» (Beck, 2000: 1). Una relación de producción precaria, insegura o informal daba cuenta de probablemente una décima parte de los empleados en Alemania de 1960, pero esa cifra alcanza hoy un 40 por ciento y sigue creciendo. Existe un problema en la manera en que Beck supone que Occidente es la norma y podríamos asimismo cuestionarnos si la «era de oro» del capitalismo fue realmente segura para los trabajadores de Occidente en 1950. No obstante, es una forma útil de aclarar los cambios provocados por la globalización y el impacto del neoliberalismo en las relaciones de producción y en las vidas de la gente trabajadora.

Lo que la brasilización significa es una inversión de la famosa máxima de Marx: «El país que está industrialmente más desarrollado no hace sino mostrar al menos desarrollado la imagen de su propio futuro» (Marx, 1970: 13). Las relaciones de producción no reguladas e informales y la generación de ingresos no son «marginales» al desarrollo capitalista ni son simplemente el privilegio dudoso del subdesarrollo. El Banco Mundial estaba mal en la teoría y en la práctica cuando afirmó que «el sector informal se encoge con 
el desarrollo» (Banco Mundial, 1995: 35). Sin duda, podemos ahora plantear el surgimiento de una nueva clase trabajadora informal global que, a tono con Davis, «es de alrededor de mil millones, lo que la convierte en la clase social de mayor crecimiento y sin precedentes del mundo» (Davis, 2007: 178). La gran expansión del sector informal a lo largo del Sur global desde la década de 1980 estuvo acompañada de su surgimiento en el Norte como una «fuerza de trabajo furtivo para la economía formal» (Davis, 2007: 178) con empresas como Walmart y otras multinacionales que creaban cadenas de bienes de primera necesidad con una gran penetración en el sector informal en el Sur. Lo que vemos ahora es un patrón que va más allá de la vieja división de lo formal y lo informal (o Norte-Sur), con una precarización continua en tanto la recesión global continúa impactando al mundo laboral.

Otra característica importante de la migración laboral contemporánea es la llamada feminización. Desde la década de 1980 hubo un incremento marcado a nivel mundial en el número de mujeres que entraban al trabajo remunerado formal en muchas regiones. La nueva división internacional del trabajo provocó un aumento significativo del empleo femenino en la industria de electrónicos en Asia del Sur y México en particular. En la década de 1990 estas tendencias se incrementaron en la medida en que la industrialización guiada por las exportaciones produjo una profunda internacionalización de las economías antes periféricas. Este proceso, comúnmente conocido como globalización, se basó en la «feminización global a través del trabajo flexible» (Standing, 1989). Con la desregulación de la economía, la retirada del Estado de las ofertas económicas y la flexibilidad se convirtieron en el nuevo lema en las relaciones laborales, por lo que también vimos un profundo cambio en los patrones de género del empleo. De forma inevitable, la composición de género de la migración, al interior de los países y entre ellos, se modificó también con las mujeres que representaban más de la mitad de la migración transnacional para 2000.

Claramente hubo muchas variaciones detrás de esta tendencia global y han surgido contratendencias desde entonces en las que los hombres predominan en algunos flujos migratorios. Sin embargo, en algunos países como Filipinas, Indonesia y Sri Lanka, las mujeres representan entre 60 y 80 por 
ciento de los migrantes. Como apunta la oIT: "Los contratos de trabajo internacionales están sumamente marcados por el género, en los que las trabajadoras son contratadas principalmente para trabajar en el sector doméstico» (OIT, 2005: 110). Las estructuras familiares están cambiando y los papeles de género «tradicionales» se están invirtiendo, particularmente en los países de origen. En los países de acogida este fenómeno ha dado lugar a una nueva ola de auto-organización política de trabajadoras domésticas migrantes (Schwenken, 2003). Este dominio, en particular, ha probado ser tierra fértil para nuevas formas de alianzas entre los sindicatos, los migrantes auto-organizados y un rango de organizaciones de apoyo, desde las cuales están surgiendo nuevos modelos.

Un paradigma social incipiente que podríamos finalmente considerar es el del "precariado», construido como un término híbrido derivado de un proletariado sujeto a condiciones laborales precarias. Está diseñado para capturar la nueva norma de trabajo inseguro y condiciones de vida frágiles/ fragmentadas (Hall-Jones, 2009). La precariedad es ahora la nueva norma en función de la permanencia, las condiciones laborales, los derechos laborales y, sin duda, la vida misma para un número creciente de trabajadores en el mundo. Los trabajadores con contratos de trabajo temporal, los trabajadores migrantes indocumentados e incluso algunos de los nuevos «teletrabajadores» forman parte de este nuevo precariado global. Las divisiones entre la gente trabajadora se profundizan en la medida en que las diferencias de nacionalidad, étnicas y de género se vuelven a articular. El sentimiento de precariedad se extiende al núcleo mismo, alguna vez seguro, del empleo «estándar» protegido. Como lo expresa Mario Candeais: «La precarización es un proceso general de desmantelamiento y polarización de los niveles de derechos sociales y estándares de vida [...]» que crea una «inseguridad en masa y un debilitamiento de la representación individual y la autoconfianza» (Candeais, 2010: 4).

El término precariado sin duda ha conducido al florecimiento de un pensamiento social crítico en torno a la condición laboral contemporánea. Apunta a los paradigmas existentes del trabajo y el desarrollo y ha roto de forma decisiva con algunas de las presunciones eurocéntricas sobre su excep- 
cionalidad. Sin embargo, todavía está puesto el foco en forma abrumadora sobre el «nuevo» precariado del Norte en los márgenes de la economía del teletrabajo y, en menor medida, en las condiciones de los trabajadores en la mayor parte del mundo. También habría que tener cuidado con las afirmaciones de que: "El precariado no es parte de la "clase trabajadora" o del "proletariado"»(Standing, 2011: 6). Esto parece implicar una comprensión esencialista del proletariado un tanto ajena al paradigma marxista clásico. Es la imagen europea del empleado varón de tiempo completo la que parece merodear detrás de esta operación de distanciamiento. Conviene recordar los problemas teóricos y políticos asociados con la categoría marxista no razonada del lumpenproletariado ${ }^{7}$ que sirvió en otra época para clasificar a los trabajadores que era difícil ubicar, pero a costa de la incoherencia teórica en relación con los trabajadores y su papel en el proceso de producción y dentro de las relaciones capitalistas de producción.

El periodo largo de globalización neoliberal y su actual desmantelamiento bajo el peso de sus propias contradicciones, ciertamente ha acentuado la inseguridad asociada con el desarrollo capitalista. Estas tendencias separatistas están ahora claramente presentes en el, alguna vez, seguro corazón capitalista de Occidente, cuando se suponían condiciones innatas del «tercer

${ }^{7}$ Lumpenproletariado es un término utilizado por Marx para describir a aquellos que se encuentran al margen de la clase trabajadora, quienes no son productivos. Para Marx quedan incluidos los «estafadores, embaucadores, dueños de burdeles, comerciantes de harapos, mendigos y otra escoria de la sociedad». La categoría representa un problema teórico para el marxismo, tanto como el concepto de "nación no histórica» tomado en préstamo a Hegel. La teoría marxista de la historia y su visión de las contradicciones del capitalismo que se despliegan son socavadas irremediablemente por ambas categorías. Recientemente, el término de lumpenproletariado fue adoptado por Frantz Fanon y algunos de los integrantes de Black Panthers. Como lo expresa Huey Newton: «Cada vez más integrantes del proletariado quedarán sin empleo, se convertirán en lumpen, hasta que se vuelvan la clase popular, los revolucionarios» (Huey Newton en un discurso dictado en Boston College, 1970). Para Fanon, el lumpenproletariado era una de las «fuerzas revolucionarias más radicales y espontáneas de un pueblo colonizado». Consideraremos si el "precariado» y el discurso sobre una nueva classé dangereux está siguiendo los pasos de este discurso y si ésta es una guía adecuada para la transformación en una era compleja de posglobalización.

$24 \frac{\text { SEGUNDO SEMESTRE } 2014}{\text { MIGRACIÓN Y DESARROLLO NÚM. } 23}$ 
mundo» donde prevalecía la «marginalidad»» en lugar de la incorporación. Sin embargo, existe algo profundamente eurocéntrico en una categoría que todavía ve al viejo proletariado como la norma y que ahora busca igualar al profesional de teletrabajo europeo de tiempo flexible a las condiciones de los «condenados de la tierra» en las megaciudades del Sur. Existe todavía una diferencia cualitativa en términos de oportunidades de vida entre los que viven en la periferia y los que viven en los principales países capitalistas, aunque estén en crisis y con Estados de bienestar degradados. En resumen, mientras que las tendencias hacia la precarización sean sin lugar a dudas globales, estamos muy lejos de la creación de un nuevo precariado global.

Una vez examinadas las mutaciones recientes del capitalismo -como un modo eminentemente histórico de producción - y su impacto en el mundo laboral, la siguiente sección aborda la complejidad de la reacción de la fuerza de trabajo. El capitalismo no se desenvuelve limpia y lógicamente de acuerdo con los esquemas de los viejos manuales marxista-leninistas. Los trabajadores, los campesinos y los migrantes, y los híbridos entre esos tres, cuentan con un grado de voluntad difícil de comprender desde una perspectiva puramente analítica. La economía política internacional, incluso en sus versiones más radicales, ha tendido a suponer un mundo sin trabajadores. La

${ }^{8}$ La teoría de la marginalidad se desarrolló a partir de la teoría de la modernización en la década de los sesenta, pero con la anterior, los teóricos de la dependencia también contribuyeron al paradigma. En tanto la primera estaba muy enfocada en la «cultura de la pobreza», la segunda hacía énfasis en la dimensión económica. En particular, José Nun (1969) argumentaba que había una separación cada vez mayor entre la élite trabajadora y la masa marginal creciente. Ésta, atraída a las ciudades por la expectativa de obtener bienes, constituía un ejército industrial de reserva de trabajadores que provocaba una disminución de los salarios y generaba más pobreza. Investigaciones empíricas llevadas a cabo en la década de los setenta pronto demostraron la falsedad de esta tesis y mostraron que la gente era pobre como producto de una inclusión perversa y asimétrica en el nuevo orden, en lugar de una exclusión. En términos teóricos, también quedó claro que había muchos enlaces entre los sectores formal e informal, en donde el último juega un papel crucial, no marginal, en la acumulación de capital (Oliveira, 1972). También se realizaron análisis inspirados por las ideas de Fanon que afirman que la «masa marginal» o los pueblos marginales podrían actuar como una nueva vanguardia revolucionaria o, desde arriba, el miedo de que se convirtieran en la nueva classé dangereux. Las transformaciones actuales bajo el auspicio del neoliberalismo han revivido el interés en el problema de la marginalidad (véase González, 2004). 
teoría del movimiento social, en su variante autonomista, ve multitudes amorfas pero deja de lado los movimientos de trabajadores organizados. Ambas corrientes parecen no darse cuenta del dominio político, como si las guerras, las revoluciones, las religiones y la geopolítica tuvieran poco impacto en la sociedad. En la siguiente sección centraremos la atención en la política con miras a desarrollar una economía política compleja del trabajo para la era de transición que estamos viviendo.

\section{COMPLEJIDAD}

La globalización, si no hizo otra cosa, centró la atención en la complejidad como un elemento fundamental de la teoría social crítica. Por un tiempo, lo global se tomaba más o menos por hecho, como una nube «ahí afuera» que de alguna manera impactaba en lo que hacíamos «acá abajo». Era vista como una deus-ex-machina, algo similar al clima que nos ofrece cielos azules (el discurso comercial) o, con mayor probabilidad, nubes negras de los trabajos que migran a otro lado. En lugar de concebir a la globalización como una entidad unificada e inequívoca, el enfoque de la complejidad nos dirige hacia la relación entre la estructura y el proceso o entre un sistema y su ambiente (Urry, 2003). En relación con el movimiento fluido de gente que llamamos migración, el enfoque de la complejidad lo concibe como una «serie de olas turbulentas, con una jerarquía de remolinos y vórtices, siendo la globalización un virus que estimula la resistencia, y el sistema migratorio una cascada que se aleja de cualquier estado de equilibrio» (Papastergiadis, citado por Urry, 2003: 62). En función del movimiento de los trabajadores, el enfoque de la complejidad nos dirigiría hacia la naturaleza dispar y combinada del desarrollo capitalista y la necesidad de una estrategia laboral de escalas múltiples. ${ }^{9}$

${ }^{9}$ El «enfoque de escalas múltiples» de los estudios sobre el trabajo global surgió de la geografía en la década de 1980. Delaney y Lechner han definido la escala como «una jerarquía entrelazada de espacios definidos que difieren en su tamaño: local, nacional y global» (Delaney y Lechner, 1997: 93). La construcción social y política de la espacialidad es percibida como una gran contribución a la comprensión de la complejidad que implica la globaliza-

$26 \frac{\text { SEGUNDO SEMESTRE } 2014}{\text { MIGRACIÓN Y DESARROLLO NÚM. } 23}$ 
La principal respuesta institucional a la precarización del trabajo a escala global ha sido el Programa de Trabajo Decente de la ort, fundada en 1919 para promover los estándares laborales diseñados para diferentes sistemas nacionales de producción. Estaba planteado para ayudar a la regulación de los mercados laborales nacionales y ofrecer protección a los empleados que supuestamente tenían un empleo estable de tiempo completo y que predominantemente eran trabajadores varones. También existía la suposición de que el modelo de Europa occidental de «asociación social» era universal. Esta era una política laboral para la era keynesiana basada en el pleno empleo integrado y la eficacia de la gestión de la política macroeconómica. En el orden mundial tan distinto de la década de 1990, después del colapso del keynesianismo, la muerte del pleno empleo y la crisis de la «competitividad», la ort lanzó el Programa de Trabajo Decente como una respuesta al predicamento laboral global. Fue un paso atrás de las directivas laborales históricas y planteó una aspiración vaga para «humanizar» la globalización a través de un conjunto de aspiraciones no ideológicas.

Sin embargo, el mundo de hoy en día no es el mundo de 1919 o incluso el de 1969 cuando la ort recibió el Premio Nobel de la Paz. Como lo expresa Guy Standing: "La orT se estableció como un medio para legitimar el laboralismo, un sistema de relaciones empleado-empleado basado en la relación de empleo estándar y un medio de sacar al trabajo del comercio internacional» (Standing, 2008: 380). Las relaciones laborales tripartitas no son con mucho el modelo dominante en la actualidad, la relación de empleo «estándar» sobrevive únicamente en pequeñas áreas, y el trabajo se trata claramente como

ción. Las categorías de escalas no deben, sin embargo, tomarse como verdades ontológicas sino como construcciones sociales. En particular, una escala (por ejemplo, la «local») no debe obtener privilegios o ser vista como social o ambientalmente "correcta». El trabajo de Andy Herod sobre la escala de la reestructuración de la política laboral en Estados Unidos (Herod, 2001) arrojó luz sobre la forma en que los movimientos laborales se relacionan con la política de escalas. Los cambios tecnológicos en los puertos durante la década de los sesenta y las rivalidades entre los sindicatos obligaron a los estibadores a cambiar de una estrategia de negociación regional a una nacional. Desde entonces, un enfoque multidisciplinario hacia la dialéctica socio-espacial de la formación del trabajo y la resistencia ha generado el inicio de un nuevo paradigma (véase McGrath-Champ, Herod y Rainnie, 2010). 
una mercancía en el mercado laboral global. Parece utópico proponer una alianza tripartita capital-Estado-trabajo en la crisis actual para crear un «trabajo decente» para todos. Parecería más ser parte de una estrategia reciente de las instituciones financieras internacionales para crear el llamado PostConsenso de Washington diseñado para superar las contradicciones de un modelo neoliberal puro. El que los sindicatos internacionales inviertan energía en esta campaña parecería fútil desde la perspectiva de los trabajadores, aunque podría bien formar parte de un sistema de alianzas políticas que el liderazgo sindical necesita forjar.

El pensamiento social crítico — conocedor de la complejidad- podría dirigirnos hacia otro camino para desarrollar una estrategia de los trabajadores y revertir los estados actuales subalternos de trabajo. Un punto de partida útil podría ser la llamada ley del desarrollo desigual y combinado, ${ }^{10}$ elaborada por primera vez por Trotsky en el contexto de la Revolución rusa. Siguiendo las ideas de Lenin en el sentido de que el capitalismo siempre se desarrolla de manera desigual en el espacio, agregó la condición de que también se «combinaba» en un sistema mundial. El imperialismo, para Trotsky, «une sin comparación, de manera más rápida y profunda, las unidades individuales nacionales y continentales en una sola entidad» (Trotsky, 1970: 20). Así, un país como Rusia a inicios del siglo xx podía presentar una amalgama compuesta de sistemas de producción arcaicos y formas más contemporáneas. También significaba que el proletariado ruso podía «saltarse etapas» y

${ }^{10}$ El desarrollo desigual y combinado fue un concepto teórico elaborado por León Trotsky para justificar las características particulares del desarrollo de la Rusia prerrevolucionaria. En contra de los marxistas ortodoxos de la Segunda Internacional, Trotsky debía mostrar que era posible la revolución en un país atrasado. El capitalismo unió bajo un mismo sistema países con niveles de desarrollo dispares. Esto no sólo aceleró la velocidad del desarrollo, sino que también le dio al país atrasado acceso a los niveles más altos de tecnología disponibles en el mundo. Para Trotsky, esta ley de desarrollo combinado significa que «hay una superposición de diferentes estadios del viaje, una combinación de etapas separadas, una amalgama de formas arcaicas con formas más contemporáneas» (Trotsky, 1970). En Rusia, el Estado y el capital entraron en contacto con sus contrapartes más avanzadas. El proletariado pudo avanzar en forma exponencial y estar en condiciones de dirigir una revolución socialista en lugar de esperar a que procediera una revolución democrática y una industrialización completa. Actualmente, esta teoría está reviviendo como parte del esfuerzo de crear una teoría marxista en las relaciones internacionales.

$28 \frac{\text { SEGUNDO SEMESTRE } 2014}{\text { MIGRACIÓN Y DESARROLLO NÚM. } 23}$ 
comenzar la construcción del socialismo sin tener que pasar por el desarrollo del capitalismo. De un golpe, Trotsky sobrepasaba la perspectiva revolucionaria dominante tanto de la Segunda como de la Tercera Internacional marxista, que por supuesto también respaldaba la teoría de la modernización predominante en la década de 1950.

Recientemente, la teoría social crítica ha agregado una dimensión espacial necesaria al análisis de la economía política del trabajo. La noción de «escalas» surgió en la década de 1990 para objetar el pensamiento tradicional de los procesos políticos y sociales. La globalización no había producido un mundo plano y las escalas local, nacional y regional de la actividad humana eran vitales. El movimiento laboral claramente opera a niveles local, nacional, subregional, regional, subglobal y global, a través de distintas formas organizativas que van desde las confederaciones de sindicatos de comercio internacional hasta las ramas sindicales locales. Estas escalas no deben ser vistas como una jerarquía y varios falsos debates alrededor de "piensa global» o «actúa de manera local» están siendo superados (véase Herod, 2001). Lo que queda claro es que las organizaciones de los trabajadores necesitan «hacer conexiones» a lo largo de las escalas. Todos los sindicalistas, por ejemplo, están de acuerdo en que el contexto global es crucial sin importar la orientación nacional o nacionalista que tengan. Asimismo, y de gran importancia para la estrategia, en la misma forma en que los países se pueden «saltar etapas», los trabajadores están ahora en condiciones de "saltarse escalas» $y$, por ejemplo, moverse de una lucha a nivel local a un nivel global.

En este mundo capitalista complejo, que no puede reducirse a una evolución unidireccional, los sindicatos también evolucionaron a través de una geometría variable tomando diferentes formas en el tiempo y el espacio. Los sindicatos surgieron como organizaciones colectivas que representaban los intereses económicos (o del lugar de trabajo) de los trabajadores. Perry Anderson alguna vez escribió: "Los sindicatos son esencialmente una representación de facto de la clase trabajadora en su lugar de trabajo» (Anderson, 1977: 335) que refleja la división capitalista del trabajo como algo dado. El desarrollo del sindicalismo político reflejó el ascenso de los partidos socialistas 
y comunistas que buscaban utilizar a los trabajadores para sus proyectos políticos. El sindicalismo político que vino después fue un reflejo de la política nacionalista de los movimientos antiimperialistas. Los trabajadores buscaban avanzar a través de la influencia benigna del Estado. Recientemente, en un contexto de una periferia que se está industrializando, hemos visto el surgimiento de un sindicalismo de movimiento social. ${ }^{11}$ Los sindicatos, desde esa perspectiva, necesitaban comprometerse con las vidas de los trabajadores fuera del lugar de trabajo y en el contexto de un Estado que no era permeable. De esta forma, los sindicatos podrían articular demandas comunitarias más amplias y forjar relaciones cercanas con organizaciones comunitarias de diferentes tipos. El desarrollo desigual y combinado de la clase trabajadora en el tiempo y el espacio ha traído al centro de la atención un sindicalismo económico, político y social en distintas combinaciones. Es esta geometría variable la que necesita ser examinada concretamente y no darse por hecho.

Sudáfrica ofrece una experiencia rica en función del repertorio de la actividad sindical. Los sindicalismos tanto políticos como sociales se desarrollaron a través de la creación de sindicatos negros independientes en la década de 1980. Iban y venían epítetos sobre el «economicismo» (la tendencia «laborista» para enfatizar las cuestiones sobre el lugar de trabajo), el "populismo» (en contra de aquellos que priorizaban el movimiento anti-apartheid más

${ }^{11}$ Sindicalismo de movimiento social es un término desarrollado por los nuevos estudios laborales internacionales en la década de los setenta que refleja las prácticas laborales radicales en Brasil, Sudáfrica y, para algunos, Filipinas (véase Munck, 1997; Seidman, 1994). En las primeras manifestaciones, reflejaba una crítica a la influencia que la historia social inglesa ha ejercido sobre la teoría de las relaciones industriales prevaleciente (Thompson, 1970). También reflejaba una crítica desde la izquierda de los sindicatos nacionalistas u orientados hacia el Estado, comunes tanto en África como en América Latina. No fue sino hasta mucho tiempo después que se codificó como una estrategia para los sindicatos, en especial por Kim Moody y su llamado a un «sindicalismo de movimiento social global» (1998). Hoy en día es un término utilizado ampliamente por los sindicatos en todas partes del mundo para expresar un deseo de una orientación más como «movimiento social» (Waterman, 1993). En ese sentido, refleja la influencia de una alterglobalización y de movimientos de justicia global «nuevos» en el movimiento laboral organizado dentro de los sindicatos.

$30 \frac{\text { SEGUNDO SEMESTRE } 2014}{\text { MIGRACIÓN Y DESARROLLO NÚM. } 23}$ 
amplio), y el sindicalismo social encontró su papel a través de boicots comunitarios a los lugares de trabajo a través de la lucha y de las huelgas llamadas stayaways (véase Webster y Lambert, 1998). El poderoso Congress of South African Trade Unions (Cosatu), pos-apartheid desde 1994, se ha visto dividido entre el papel político como asociado a la limpieza del gobierno del Congreso Nacional Africano (ANC, por sus siglas en inglés) y su papel de representante de los intereses económicos de sus miembros (véase Pillay, 2012). La división entre la política de producción y la política de Estado por momentos parece aguda. Otra división es la existente entre la clase trabajadora organizada y la creciente fuerza de trabajo migrante precaria. Hasta ahora sólo hemos visto el brillo ocasional, o para ser precisos, declaraciones en conferencias, del sindicalismo social de la década de 1980, que jugó un papel vital en la construcción de una voluntad popular y nacional en contra del apartheid.

En América Latina, en un momento y contexto similares, el sindicalismo social se desarrolló como una respuesta a los regímenes militares autoritarios y al desarrollo del «capitalismo salvaje». Esto fue especialmente notable en Brasil con el sindicalismo nuevo de la década de 1980, que estableció lazos con la Iglesia y los grupos comunitarios para luego formar el Partido de los Trabajadores. La reestructuración neoliberal debilitó a éstas y a otras formaciones laborales en la década de 1990. Sin embargo, desde entonces ha habido una marcada insurgencia del empleo tanto con enlaces verticales (desde el nivel nacional al regional al de la ciudad) y horizontales (entre sectores y luchas sociales más amplias) que se convierten en una característica común, al menos en Brasil y los países del Cono Sur (véase Fernández, 2007). Otra corriente política que surgió en este periodo fue la basada en el «autonomismo» ${ }^{12}$ representado en mayor medida por los zapatistas en México

${ }^{12} \mathrm{El}$ autonomismo era una organización política de extrema izquierda en Italia que surgió a finales de la década de 1960 del ala obrerista (operaísmo) del comunismo. Su principal característica era la creencia de que la clase trabajadora era, o podía ser, un agente autónomo de la transformación social, independiente del Estado, los sindicatos y los partidos políticos. También alejó la atención del repertorio racionalizado del movimiento laboral de huelgas y marchas para enfatizar formas más difusas de resistencia de la clase trabajadora, tales como el absentismo y la huelga de celo. A través del concepto de «obrero social» los auto- 
y en menor medida por los piqueteros en Argentina. Con su creencia nietzscheana en una «multitud» fuera de los límites de la política, esta corriente al final se ha marginado a sí misma. En los países andinos (Bolivia y Ecuador), los sindicatos y los movimientos indígenas han elaborado articulaciones políticas desde una izquierda revitalizada que intenta tomar el poder estatal y comenzar un proceso serio de transformación social.

Entre tanto, en el corazón mismo del capitalismo avanzado, el impacto del neoliberalismo - incluida la «exportación» de trabajadores y la «importación» de trabajadores extranjeros- llevó al surgimiento de un nuevo o quizás reinventado «sindicalismo comunitario». ${ }^{13}$ En Estados Unidos, la Federación Estadounidense del Trabajo y el Congreso de Organizaciones Industriales (AFL-Clo, por sus siglas en inglés), atravesó una transformación de su liderazgo que la llevó más allá del «sindicalismo de negocios» que la caracterizaba y le siguieron las alianzas con los trabajadores latinoamericanos, alguna vez impensables. Por todas partes del país los sindicatos locales y nacionales

nomistas italianos (Mario Tronti, Sergio Bologna, Antonio Negri et al.) extendieron el concepto marxista tradicional de clase trabajadora. Las autonomistas feministas (Mariarosa Dalla Costa) extendieron todavía más el concepto al incorporar al trabajo doméstico femenino no remunerado en la categoría de trabajo. El trabajo actual de Antonio Negri y, en forma más general y difusa, la corriente autonomista, tiene influencia en los estudios laborales actuales, y no menos en relación con el surgimiento de un precariado.

${ }^{13} \mathrm{El}$ sindicalismo comunitario es un término usado tanto en Estados Unidos como en Reino Unido para referirse a las prácticas sindicales recientes de involucrarse con varios actores de la comunidad. En tanto tienen raíces históricas en las prácticas del movimiento laboral, se considera particularmente adecuado para un periodo de fragmentación del mercado laboral y de polarización dentro y entre comunidades. Los enlaces sindicato-comunidad pueden ser alianzas estratégicas a corto plazo o por periodos más largos. Una modalidad está representada por el Workers Rights Centres en Estados Unidos, que con frecuencia se enfoca en las necesidades de los trabajadores migrantes. Estas relaciones pueden algunas veces ser tensas cuando se hacen con las organizaciones comunitarias (por ejemplo, de migrantes) que ven a los movimientos sindicalistas como representantes de una "aristocracia laboral», en tanto los sindicatos pueden ver a las organizaciones comunitarias como entidades no electas, no representadas y faltas de responsabilidad. Sin embargo, muchas experiencias de «sindicalismo comunitario» de largo plazo han demostrado ser transformadoras para los sindicatos que tienden a adquirir una noción más compleja y amplia del mundo laboral y el medio para hacer avanzar al movimiento de los trabajadores (véase McBride y Greenwood, 2009; Milkman, 2011). 
forjaron alianzas con las organizaciones de trabajadores migrantes, dando lugar a los centros de trabajadores (véase Fine, 2005). También había que hacer un llamamiento a una tradición estadounidense de actividad de base, como la campaña por las «ciudades sindicales». ${ }^{14}$ En Reino Unido, un movimiento sindicalista con fuerte tendencia laborista comenzó a explorar en forma esporádica alianzas con asociaciones de trabajadores migrantes y los movimientos muchas veces basados en la fe que apoyaban a aquéllas (véase McBride y Greenwood, 2009). También en ese caso, sindicalismo comunitario fue el término que predominó para describir lo que básicamente era el sindicalismo social del que hablamos arriba, que expande - no necesariamente sustituye - el sindicalismo económico básico y el sindicalismo político en apoyo al Partido Laboralista.

Este no es el lugar para sacar conclusiones simplistas: claramente el tenor de mi argumento es presentar cuestiones a debate. En muchas arenas sociales y políticas estos y otros debates similares se están llevando a cabo en la práctica. Su resultado es inevitablemente incierto. En términos de los retos presentados al inicio, considero que hemos delineado una posible respuesta con base en las luchas sociales reales y en una teoría crítica abierta. Las estrategias laborales existentes, fundadas en viejos modelos y en un eurocentrismo moribundo, seguramente no lograrán alcanzar sus objetivos. La agitación global actual está arrojando una crisis existencial del capitalismo

${ }^{14}$ Las ciudades sindicales son formas antiguas/nuevas de operación de los sindicatos a nivel de ciudad y son particularmente comunes en Estados Unidos y Reino Unido. Son expresiones territoriales — no por lugar de trabajo- del poder y la política de los sindicatos. En Estados Unidos existen consejos centrales laborales en la mayoría de las ciudades, en tanto que en Reino Unido son denominadas Trades Councils. Son la expresión local de los cuerpos sindicales nacionales de AFI-CLO y TUC, respectivamente. Con frecuencia, estos cuerpos son débiles y se enfocan en la rutina política local para forjar relaciones con los líderes comerciales locales. Sin embargo, ocasionalmente entran en acción, como lo hizo el Milwaukee County Labour Council en la década de 1990 a través de un liderazgo cercano a los movimientos de derechos civiles, con lo que comenzó a actuar como un contrapeso serio a la comunidad comercial local. Ahora que los poderes gubernamentales están siendo conferidos a las autoridades locales de crecimiento y que se están formando coaliciones de crecimiento urbano a nivel de ciudad, es el momento propicio para el resurgimiento de esta expresión territorial del movimiento laboral. Ahora son parte de un movimiento más grande que crea "furor callejero» sobre la crisis económica que se desarrolla actualmente. 
global tal como lo conocemos y un desafío serio para las naciones y las clases subalternas. La precarización del trabajo no es sino apenas una hebra de una mutación compleja del capitalismo en curso. Por lo tanto, los sindicatos necesitarán comprometerse con la economía política de la migración laboral como lo hemos apuntado y también con un rango mucho más amplio de eventos dramáticos, incluidos la guerra y la revolución.

\section{Bibliografía}

Almeyra, Guillermo (2008), "Los vaivenes de los movimientos sociales en México», OSAL, vol. 9, núm. 4, pp. 87-101.

Anderson, Perry (1977), "The Limits and Possibilities of Trade Union Action», en T.

Clarke y L. Clements (eds.), Trade Unions under Capitalism, Londres, Fontana, pp. 333-350.

Arrighi, Giovanni (1990), «Marxist Century, American Century: The Making and Remaking of the World Labour Movement», New Left Review, vol. 179, núm. 1, pp. 29-63.

BanajI, Jairus (2011), Theory as History. Essays on Modes of Production and Exploitation, Chicago, Haymarket Books.

Beck, Ulrich (2000), The Brave New World of Work, Cambridge, Polity Press.

Blackburn, Robin (2011b), «Crisis 2.0», New Left Review, núm. 72, pp. 33-62.

Bremen, Jan (2009), "Myth of the Global Safety Net», New Left Review, núm. 59, pp. 29-36.

CAndeias, Felipe (2010), "Double Precariation of Labour: Perspectives of Expanded (Re) appropriation», en http://www.rosalux.de/fileadmin/wgdw_uploads/ Double_precarisation.pdf (consultado el 4 de agosto de 2014).

Castells, Manuel (1996), The Rise of the Network Society, Oxford, Blackwell.

Castles, Stephen (2010), «Understanding Global Migration: A Social Transformation Perspective», Journal of Ethnic and Migration Studies, vol. 36, núm. 10, pp. 1565-1586.

DAvid, Noel (2002), «Migrants Get Trade Unions Back to Basics», Labour Education, núm. 129, Ginebra, ILo.

DAvis, Mike (2006), Planet of Slums, Nueva York, Verso.

$34 \frac{\text { SEGUNDO SEMESTRE } 2014}{\text { MIGRACIÓN Y DESARROLLO NÚM. } 23}$ 
(2011), «Spring Confronts Winter», New Left Review, núm. 72, pp. 5-15.

Delaney, David y Francis Lechner (1997), «The Social Construction of Scale», Political Geography, núm. 16, pp. 93-97.

Farmer, David y A. W. Lo (1999), «Frontiers of Finance: Evolution and Efficient Markets», Proceedings of the National Academy of Sciences, vol. 96, núm. 10, pp. 9991-9992.

Fernández, Arturo (ed.) (2007), Estados y sindicatos en perspectiva latinoamericana, Buenos Aires, Corregidor.

Fine, Jane (2005), "Community Unions and the Revival of the American Labor Movement», Politics and Society, vol. 33, núm. 1, pp. 153-199.

Frege, Carol y John Kelly (2003), «Union Revitalization in Comparative Perspective», European Journal of Industrial Relations, vol. 9, núm. 1, pp. 7-24.

Friedman, George (2008), Reigniting the Labour Movement. Restoring means to ends in Democratic Labour Movement, Londres, Routledge.

Godio, Julio (2005), Sociedades de trabajo y sindicalismo socio-político en América Latina y el Caribe, Buenos Aires, Corregidor.

GonzÁlez, G. R. et al. (2004), "From the Marginality of the 1960's to the "New Poverty of today"”, Latin American Research Review, vol. 39, núm. 1, p. 183.

Gramsci, Antonio (1970), Selections from the Prison Notebooks, Londres, Lawrence \& Wishart.

Hall-Jones, Peter (2009), "Precariat Meet'n'Greet», New Unionism Blog, en https:// newunionism.wordpress.com/2009/11/22/precariat/ (consultado el 8 de diciembre de 2013).

Hard, Michael y Antonio Negri (2001), Empire, Cambridge, Massachussets, Harvard University Press.

Harvey, David (2003), The New Imperialism, Oxford, Clarendon Press.

(2010), The Enigma of Capital and the Crisis of Capitalism, Londres, Verso.

Herod, Andy (2001), Labour Geographies. Workers and the Land Scopes of Capitalism, Guildford, Guildford University Press.

IOM (2005), World Migration. Costs and Benefits of International Migration, Ginebra, IOM. KenneDy, David (2001), «The International Human Rights Movement: Part of the Problem?», Human Rights Law Review, núm. 3.

LaClau, Ernesto (2005), On Populist Reason, Londres, Verso. (2011), Debates y combates. Por un horizonte de la política, México, Fondo de Cultura Económica. 
Linden, Marcel V. (2003), Transnational Labour History, Aldershot, Ashgate.

Lutz, Helma, M. T. Herrera Vivar y L. Supik (eds.) (2011), Framing Intersectionality: Debates on a Multi-Faceted Concept in Gender Studies, Farnham, Ashgate.

Luxemburgo, Rosa (1970), The Accumulation of Capital, Londres, Routledge.

Lyons, Linda (2006), «The Limits of Transnational Activism: Organizing for Migrant Workers Rights in Malaysia and Singapore», Transnationalization of Solidarities and Women Movements Workshop, University of Montreal.

MarX, Karl (1970), Capital, vol. 1, Londres, Penguin.

McBride, Jo y I. Greenwood (eds.) (2009), Community Unionism. A Comparative Analysis of Concepts and Contexts, Londres, Palgrave Macmillan.

McGrath-Champ, Susan, Andy Herod y Al Rainnie (eds.) (2010), Handbook of Employment and Society: Working Space, Cheltenham, Edward Elgar.

Milanovic, Branko (2011), «Global Inequality from Class to Location, from Proletarians to Migrants», Policy Research Working Paper 5820, Ginebra, Banco Mundial.

Mitkman, Ruth (2011), «Immigrant Workers, Precarious Work and the US», en R. Munck, C. Scierup y R. Delgado Wise (eds.), Migration, Work and Citizenship in the New Global Order, Londres, Routledge.

Moody, Kim (1997), Workers in a Lean World: Unions in the International Economy, Londres, Verso.

Munck, Ronaldo (1997), The New International Labour Studies, Londres, Zed Books. (2002), Labour and Globalisation: The New Great Transformation, Londres, Zed Books.

(2011), «Beyond North and South: Migration, Informalization and Trade Union Revitalization», Working USA: The Journal of Labor and Society, vol. 14, núm. 1, pp. 5-18.

Nun, José (1969), «Superpoblación relativa, ejército industrial de reserva y masa marginal», Revista Latinoamericana de Sociología, núm. 2.

Organización Internacional de Trabajo (OIT) (s/f), El Programa de Trabajo Decente, en http://www.ilo.org/global/about-the-ilo/decent-work-agenda/lang--es/index. htm consultado el 14 de septiembre de 2014.

Oliveira, Francisco (1972), "A Economia Brasileira: Critica a Razao Dualista», Estudios CEBRAP, núm. 2.

Penninx, Rinus y Judith Roosblad (eds.) (2000), Trade Unions and Immigration in Europe, 1960-1993, Nueva York, Bergham Books.

$36 \frac{\text { SEGUNDO SEMESTRE } 2014}{\text { MIGRACIÓN Y DESARROLLO NÚM. } 23}$ 
Pillay, Devan (2012), «Working Class Politics in South Africa: the Return of Social Movement Unionism?», Labour, Capital and Society, núm. 2, p. 44.

Piper, Nicola (2009), «Social Development, Transnational Migration and the Political Organising of Foreign Workers», Documento No. 39, Ginebra, UNRISD.

PolanyI, Karl (2001), The Great Transformation: The Economic and Political Origins of our Time, Boston, Beacon.

RugGiE, James (1984), «International Regimes, Transitions and Change: Embedded Liberalism in the Postwar Economic Order», International Organization, vol. 36, núm. 2, pp. 397-415.

Santos, Boaventura S. (ed.) (2006), Another Production is Possible, Beyond the Capitalist Canon, Londres, Verso.

Schwenken, Helen (2003), «Respect for All: The Political Self Organization of Female Migrant Domestic Workers in the European Union", Refuge, vol. 20, núm. 3. Seidman, Gay (1994), Manufacturing Militance: Workers' Movements in Brazil and South Africa, Berkeley, California University Press.

SiLver, Beverley (2003), Forces of Labor: Workers Movements and Globalization Since 1870, Cambridge, Cambridge University Press.

Standing, Guy (1989), «Global Feminization Through Flexible Labour», World Development, vol. 17, núm. 7, pp. 1077-1095.

(2008), «The ILO: An Agency for Globalization?», Development and Change, vol. 39, núm. 3, pp. 355-394.

(2011), The Precariat. The New Dangerous Class, Londres, Bloomsbury Academic.

Thompson, Edward P. (1970), The Making of the English Working Class, Harmondsworth, Penguin.

Trotsky, Leon (1970), The History of the Russian Revolution, Londres, Pathfinder.

URRY, John (2003), Global Complexity, Cambridge, Polity Press.

Wacouant, Loic (2007), «Territorial Stigmatization in the Age of Advanced Marginality", Thesis Eleven, vol. 91, pp. 66-77.

WADE, Robert (2008), «Financial Regime Change?», New Left Review, núm. 53.

Waterman, Peter (1993), «Social-Movement Unionism: A New Union Model for a New World Order», Review, vol. 16, núm. 3.

Webster, Eddie y Rob Lambert (1988), «The Re-Emergence of Political Unionism in Contemporary South Africa», en W. Cobbett y R. Cohen (eds.), Popular Struggles in South Africa, Londres, Currey. 
RONALDO MUNCK

Webster, Eddie, R. Lambert y A. Bezuidenhout (2008), Grounding Globalization: Labour in the Age of Insecurity, Oxford, Blackwell.

Wordd Bank (1995), World Development Report 1995: Workers in a Lean World, Nueva York, World Bank. 